\title{
Spatial structure of summertime ionospheric plasma near magnetic noon
}

\author{
R. W. Sims ${ }^{1, *}$, S. E. Pryse ${ }^{1}$, and W. F. Denig ${ }^{2}$ \\ ${ }^{1}$ Institute of Mathematical and Physical Sciences, University of Wales Aberystwyth, SY23 3BZ, UK \\ ${ }^{2}$ Space Vehicles Directorate, Air Force Research Laboratory, Hanscom AFB, Massachusetts, USA \\ *now at: Medical Physics Directorate, University Hospital of North Staffordshire, ST4 7LN, UK
}

Received: 10 October 2003 - Revised: 14 May 2004 - Accepted: 2 July 2004 - Published: 31 January 2005

Part of Special Issue "Eleventh International EISCAT Workshop"

\begin{abstract}
Results are presented from a multi-instrument study of the spatial distribution of the summertime, polar ionospheric electron density under conditions of relatively stable IMF $B_{z}<0$. The EISCAT Svalbard radar revealed a region of enhanced densities near magnetic noon that, when comparing radar scans from different local times, appeared to be spatially confined in longitude. This was identified as the tongue-of-ionisation (TOI) that comprised photoionisation of sub-auroral origin that is drawn poleward into the polar cap by the anti-sunward flow of the high-latitude convection. The TOI was bounded in longitude by high-latitude troughs; the pre-noon trough on the morning side with a minimum near $78^{\circ} \mathrm{N}$ and the post-noon trough on the afternoon side with a minimum at $80^{\circ} \mathrm{N}$. Complementary measurements by radio tomography, the SuperDARN radars, and a DMSP satellite, together with comparisons with earlier modelling work, provided supporting evidence for the interpretation of the density structuring, and highlighted the role of plasma convection in the formation of summertime plasma distribution. Soft particle precipitation played only a secondary role in the modulation of the large summertime densities entering the polar cap.
\end{abstract}

Key words. Ionosphere (Plasma convection; Plasma temperature and density; Polar ionosphere)

\section{Introduction}

The polar ionosphere is a highly-structured medium that comprises electron density irregularities on a wide range of horizontal spatial scales (Tsunoda, 1988). The current study is concerned with dayside F-region density structures on horizontal scales of tens to hundreds of kilometers in

Correspondence to: S. E. Pryse

(sep@aber.ac.uk) the magnetic noon sector under conditions of Interplanetary Magnetic Field (IMF) $B_{z}<0$. Of particular interest is the tongue-of-ionisation (TOI), transporting photoionisation from sub-auroral latitudes into the polar cap, that separates the high-latitude density troughs in the pre- and post-noon time sector.

The source of the large polar electron densities has been investigated during the past twenty years, and early groundbased observations of polar F-region ionisation under conditions of IMF $B_{z}<0$ have revealed patches of high electron density (Buchau et al., 1983, 1988). Soft-particle precipitation in sub-polar regions has been cited as a possible source for polar ionisation, with the less energetic incoming particles giving rise to enhanced density at high altitudes where the lifetime of plasma is sufficiently long for it to be transported over the polar cap (Weber et al., 1984). In this instance, it was suggested that there may be sufficient time for the plasma density to build-up if sunward convecting fluxtubes move along the cusp region for tens of minutes before turning anti-sunward into the polar cap. However, it is now widely accepted that the bulk of the ionisation within the polar cap originates from the transport of photoionisation from sub-auroral latitudes, and not direct soft particle precipitation in the vicinity of the cusp (Knudsen, 1974; Kelly and Vickrey, 1984; Whalen, 1994). Foster (1984) presented average maps of convection and F-region electron density at auroral latitudes from the Chatanika radar. A region of enhanced photoionisation was observed to form in the post-noon time sector near a region of flow stagnation. This region of enhancement subsequently formed a tongue, similar to that first identified by Sato (1959), that was observed to move through the cleft and populate the polar cap with fresh Fregion plasma near magnetic noon. Further detailed studies using incoherent scatter radar observations support photoionisation convection poleward through the cleft as a source of polar-cap ionisation (Foster, 1993, and references therein). 
More recently, a multi-instrument approach by Pryse et al. (2004) presented circumstantial evidence for the TOI in the magnetic noon sector. Radio tomographic imaging identified a ridge of enhanced densities at sub-auroral latitudes that were suggested to form in a region of slow-moving plasma slightly poleward of a region of stagnation. To the authors knowledge there have been no EISCAT observations of the latitudinal structure of the TOI in the literature.

Several authors have cited possible mechanisms for the creation of patches from the continuous plasma stream of the TOI. Sojka et al. (1994) used the Time-Dependent Ionospheric Model (TDIM) to illustrate how temporal variations in IMF $B_{y}$ can cause the shearing of the TOI into features consistent with polar patches (Crowley, 1996). Rodger et al. (1994) described how high-velocity flow channel events are able to cause enhanced rates of plasma recombination that effectively fragments the ionisation into patches. Anderson et al. (1988) suggested that an expansion of the high-latitude convection pattern into a region of photoionisation at subauroral latitudes, and then its subsequent contraction, could give rise to patch-like structures in the polar cap. A variation by Lockwood and Carlson (1992) suggested that the expansion of the convection pattern could be controlled by pulsed dayside magnetopause reconnection. Soft particle precipitation within the cusp may also contribute to patch formation, although there remains controversy surrounding the extent to which it modulates the electron density (Walker et al., 1999; Smith et al., 2000; Nielsen et al., sumitted, 2003 ${ }^{1}$ ). The UT and seasonal modulation of polar patches has been modelled by Sojka et al. (1994) where patches were most marked during winter solstice between 20:00-24:00 UT. Subsequent modelling during winter conditions investigated the effects of IMF $B_{y}$ and the location of the observing site (Bowline et al., 1996). These results suggested that the patches, and hence TOI, were most marked between 17:00-22:00 UT but were almost absent near magnetic noon during conditions of IMF $B_{y}>0$ at Ny $\AA$ Alesund. However, a multi-instrument case study by Pryse et al. (2004) provided circumstantial evidence for the TOI above Svalbard near magnetic noon in winter, and whilst the patch-to-background ratio measured was considerably less than that predicted for 17:00-22:00 UT, it was broadly in agreement with the ratio modelled at $\mathrm{Ny}$ Allesund and with the patch criterion of Crowley (1996) of density two-fold above background.

Regions of depleted F-region electron density that bound the TOI at sub-polar latitudes are referred to as high-latitude density troughs (Whalen, 1994). These troughs are discussed in the review paper by Rodger et al. (1992) where the roles of flow stagnation and enhanced electric fields are cited as being important for their formation. Unlike the main, midlatitude trough that has a reasonably well-defined morphology (Moffett and Quegan, 1983), the high-latitude troughs are less studied and not so-well understood, owing to the lack

\footnotetext{
${ }^{1}$ Nielsen, C., Moen, J., Carlson, H., Oksavik, K., Gallop, P., and Denig, W.: Patch formation in relation to cusp auroral activity, Ann. Geophys. submitted, 2003.
}

of observations in remote and inhospitable locations. One of the largest databases was recorded during the International Geophysical Year 1958 when an extensive array of groundbased sounders were used to provide maps of $f o \mathrm{~F} 2$ over extended areas. Data from the high-latitude sites were considered by Whalen $(1987,1989,1994)$ in the investigation of high-latitude troughs in relation to high-latitude convection. Whalen (1987) identified a longitudinal variation in a trough location, attributed to the offset between the geomagnetic co-ordinate system, in which the high-latitude convection pattern resides, and the geographic coordinate system. Subsequently, Whalen (1989) proposed that these troughs occur in regions where the sunward convective flow was carrying low-density plasma from the nightside to displace regions of high-density daytime plasma. The relationship between these density troughs and the TOI was then reported by Whalen (1994), who suggested that the maximum density of the ridge of ionisation that comprises the TOI had a seasonal dependence consistent with ionisation by solar radiation, and a local time dependance that was consistent with the transport from elsewhere rather than local production.

Several incoherent scatter observations have presented regions of depleted F-region electron density near the noon sector. In these experiments the high-latitude trough occurred on sunward convecting field lines equatorward of the convection reversal boundary (CRB) in both the pre- and post-noon time sectors (Kelly and Vickrey, 1984; Foster and Doupnik, 1984; Foster et al., 1989). However, the review by Rodger et al. (1992) suggested that although the high-latitude trough does occur on sunward convecting field lines in the post-noon time sector, it often occurs in close proximity to the CRB and $30 \mathrm{keV}$ electron trapping boundary in the prenoon time sector. Radio tomography has imaged the latitudinal structure of the post-noon high-latitude trough under quiet geomagnetic conditions (Pryse et al., 1998). Comparison of the trough location with the Izmiran electrodynamic model (IZMEM) suggested that the trough was coincident with a regime of sunward convective flow in the post-noon time sector. Recent tomographic studies suggest that the post-noon trough is a persistent feature in winter, residing entirely within a regime of sunward return convective flow (Sims, 2003), with its poleward wall being modulated by soft auroral precipitation and the equatorward wall governed by photoionisation.

The results presented in this paper focus on the largescale spatial structure of the dayside summertime ionosphere made by the EISCAT Svalbard radar (ESR) broadly between 06:30-09:30 UT on the 26 August 2000. The geomagnetic conditions during this period were quiet, with a $K_{p}$ index of 1+. A new aspect are observations of electron density along the TOI bounded on either side by the pre- and post-noon high-latitude troughs. Simultaneous observations by radio tomography, the SuperDARN HF radars and a satellite from the Defence Meteorological Satellite Program (DMSP) constellation have provided additional support for the interpretation of the density structures. 


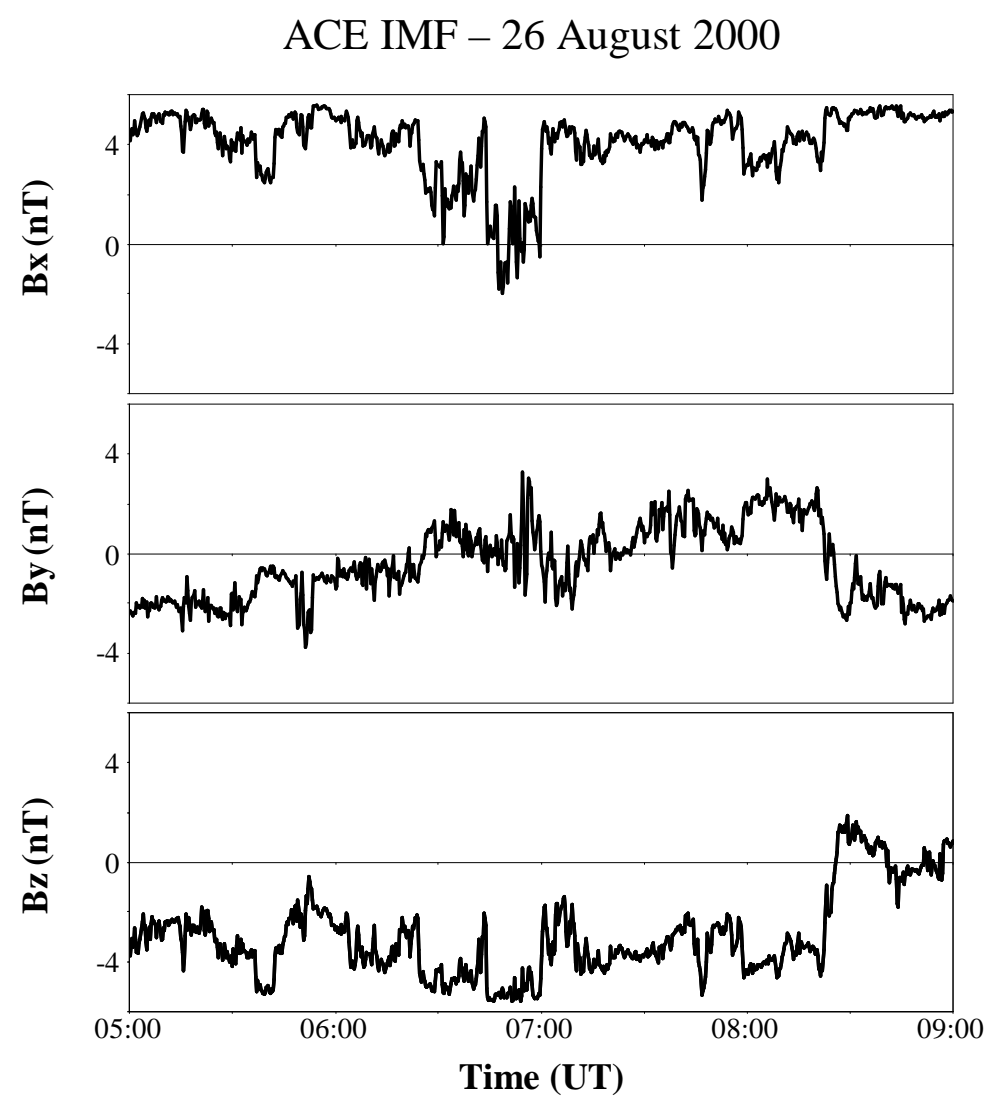

Fig. 1. The three components of the IMF measured by the ACE spacecraft upstream in the solar wind between 05:00-09:00 UT on 26 August 2000.

\section{Experimental observations}

\subsection{Interplanetary Magnetic Field}

The three components of the IMF measured by the ACE spacecraft between 05:00-09:00 UT are shown in the three panels of Fig. 1. Of particular interest to the current study is the negative $B_{z}$ component of between -2 and $-5 \mathrm{nT}$ during the interval 05:00-08:20 UT, commensurate with equatorial magnetopause reconnection. At this time there is a weak trend in the $B_{y}$ component from -2 to $+2 \mathrm{nT}$ with multiple zero crossings, centered approximately at 07:00 UT. The $B_{x}$ component is positive, apart from a brief negative excursion around 06:50 UT. The spacecraft was positioned upstream of the Earth in the solar wind at approximately $240 R_{E}$, where it measured an essentially constant solar wind velocity of $390 \mathrm{kms}^{-1}$. Simple calculations estimate the time delay between these observations and the corresponding ionospheric response to be approximately $67 \mathrm{~min}$, with more detailed calculations using a procedure similar to that described by Lockwood et al. (1989) suggesting a time delay closer to $73 \mathrm{~min}$. For the time scales appropriate to this study a time delay of $70 \mathrm{~min}$ has been used.
2.2 Electron density at auroral and sub-auroral latitudes

\subsubsection{EISCAT Svalbard radar}

The EISCAT Svalbard radar $\left(78.2^{\circ} \mathrm{N}, 16.1^{\circ} \mathrm{E}, 75.0^{\circ} \mathrm{MLAT}\right.$, $113.1^{\circ} \mathrm{MLON}$ ) was operating in the NOON UK special programme mode broadly between 06:30-09:30 UT. The steerable 32-m antenna scanned from north-to-south of zenith along the local geographic meridian in cycles of approximately twenty minutes. Each meridional scan comprises 38 pointing directions corresponding to latitudinal steps of $0.19^{\circ}$ at an altitude of $300 \mathrm{~km}$. The measured electron densities and temperatures, post-integrated over 2 scan positions for improved signal-to-noise ratio, are shown in Figs. 2 and 3 , respectively. The $300-\mathrm{km}$ ray-path intersection for successive radar scans are shown on a MLAT versus MLT polar grid broadly between 09:00-13:00 MLT in Fig. 4, with the first and last scan labelled 1 and 9, respectively. The alignment of successive radar scans away from the magnetic meridian is due to the geographic scanning operation of the radar, rotating the northern part of the scan to the east of the magnetic pole and the southern part of the scan to the west, resulting in each scan spanning a small $(<1 \mathrm{~h})$ MLT region.

The first two electron density scans starting at 06:31 UT and 06:51 UT indicate low densities of around $2.0 \times 10^{11} \mathrm{~m}^{-3}$ 

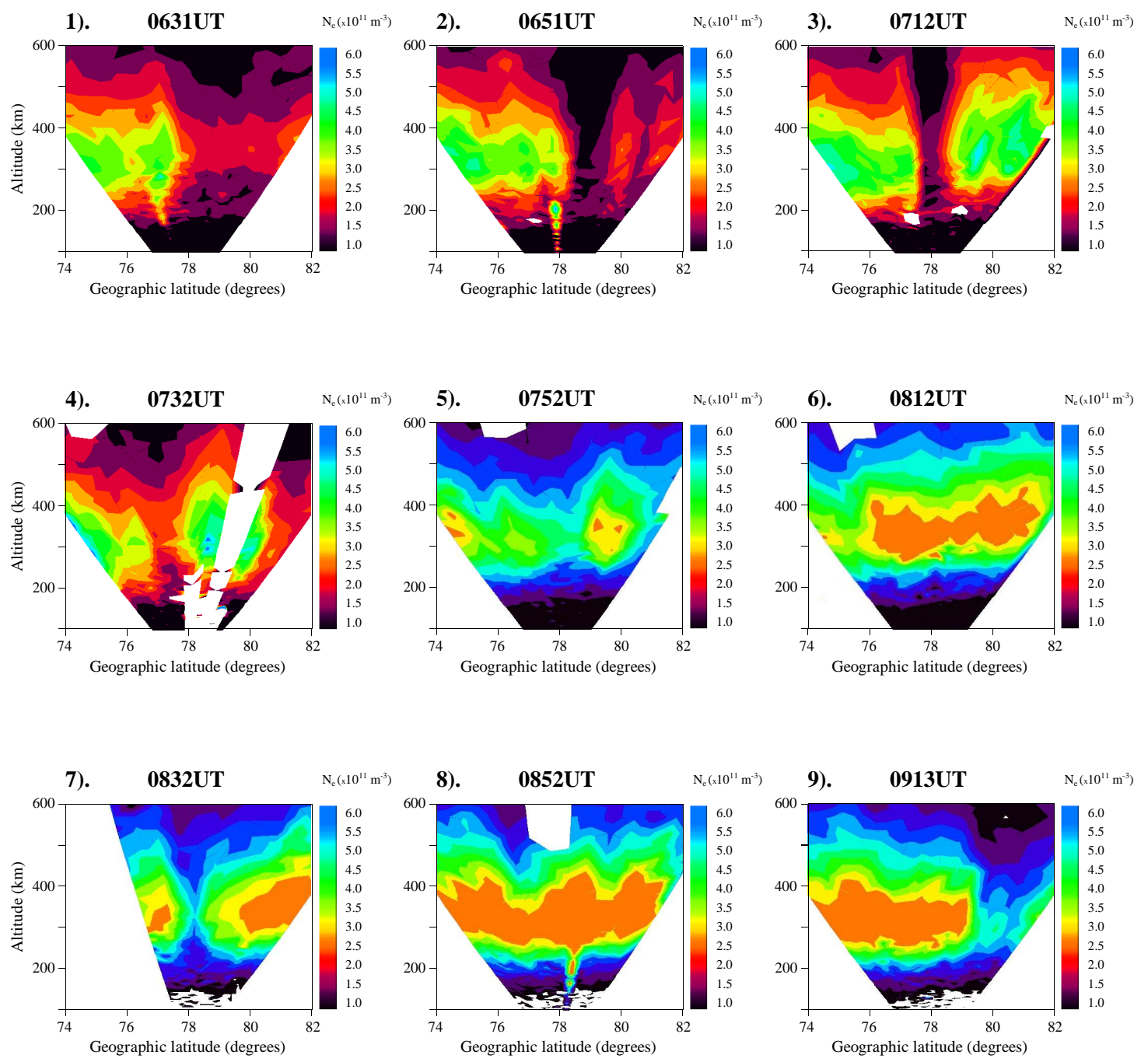

Fig. 2. Electron densities measured by the ESR during successive latitudinal scans of the radar beam in the NOOK UK special programme broadly between 06:30-09:30 UT on 26 August 2000. The start time for each scan where the radar beam is at its most northerly position is shown on the figure.

poleward of $78.0^{\circ} \mathrm{N}\left(\sim 75.0^{\circ}\right.$ MLAT $)$ with increased levels of nearer $2.5 \times 10^{11} \mathrm{~m}^{-3}$ at the northern extreme of the field-ofview. A broad region of enhanced F-region electron densities occur at lower latitudes with evidence for finer structuring broadly between $76.0^{\circ}-78.0^{\circ} \mathrm{N}\left(\sim 73.0^{\circ}-75.0^{\circ} \mathrm{MLAT}\right)$. The striking feature in the third scan starting at 07:12 UT is the abrupt appearance of a dense patch of plasma at high altitudes and latitudes located between $78.5^{\circ}-81.5^{\circ} \mathrm{N}\left(\sim 75.5^{\circ}-\right.$ $78.5^{\circ}$ MLAT) near 10:30 MLT in the pre-noon time sector (see Fig. 4). This feature has a maximum density of $5.5 \times 10^{11} \mathrm{~m}^{-3}$ at a height of $360 \mathrm{~km}$ with a relatively sharp bottomside density profile near $250 \mathrm{~km}$. Its presence produces a narrow density trough just to the south of some $1.0^{\circ}$ latitude wide, with a peak density of $1.5 \times 10^{11} \mathrm{~m}^{-3}$. The dense patch of plasma and narrow density trough are observed at slightly lower latitudes and altitudes by the next radar scan starting at 07:32 UT, with electron densities of $6.0 \times 10^{11} \mathrm{~m}^{-3}$ and $2.5 \times 10^{11} \mathrm{~m}^{-3}$, respectively. Twenty minutes later during the radar scan starting at 07:52 UT the density trough is no longer discernable from the surrounding ionospheric structure. A relatively uniform region of electron density now extends over the entire latitudinal field-ofview with a small gradient in the F-region peak increasing in height with latitude. This gradient is much clearer by the scan starting at 08:12 UT, where electron densities in excess of $6.0 \times 10^{11} \mathrm{~m}^{-3}$ generally extend from low to high latitudes along the scan. There is some evidence for the modulation of this band of high densities on smaller spatial scales, and a hint of a poleward edge to the ionisation at the northern extreme of the field-of-view. The electron densities continue to increase to nearly $9.0 \times 10^{11} \mathrm{~m}^{-3}$ by the scan starting at 08:52 UT, with detailed analysis suggesting no significant latitudinal structure. This region of very high densities is interrupted only with the abrupt appearance of a density trough near $78.0^{\circ} \mathrm{N}\left(\sim 75.0^{\circ}\right.$ MLAT $)$ during the scan at 08:32 UT which will be discussed at a later stage. By the last 

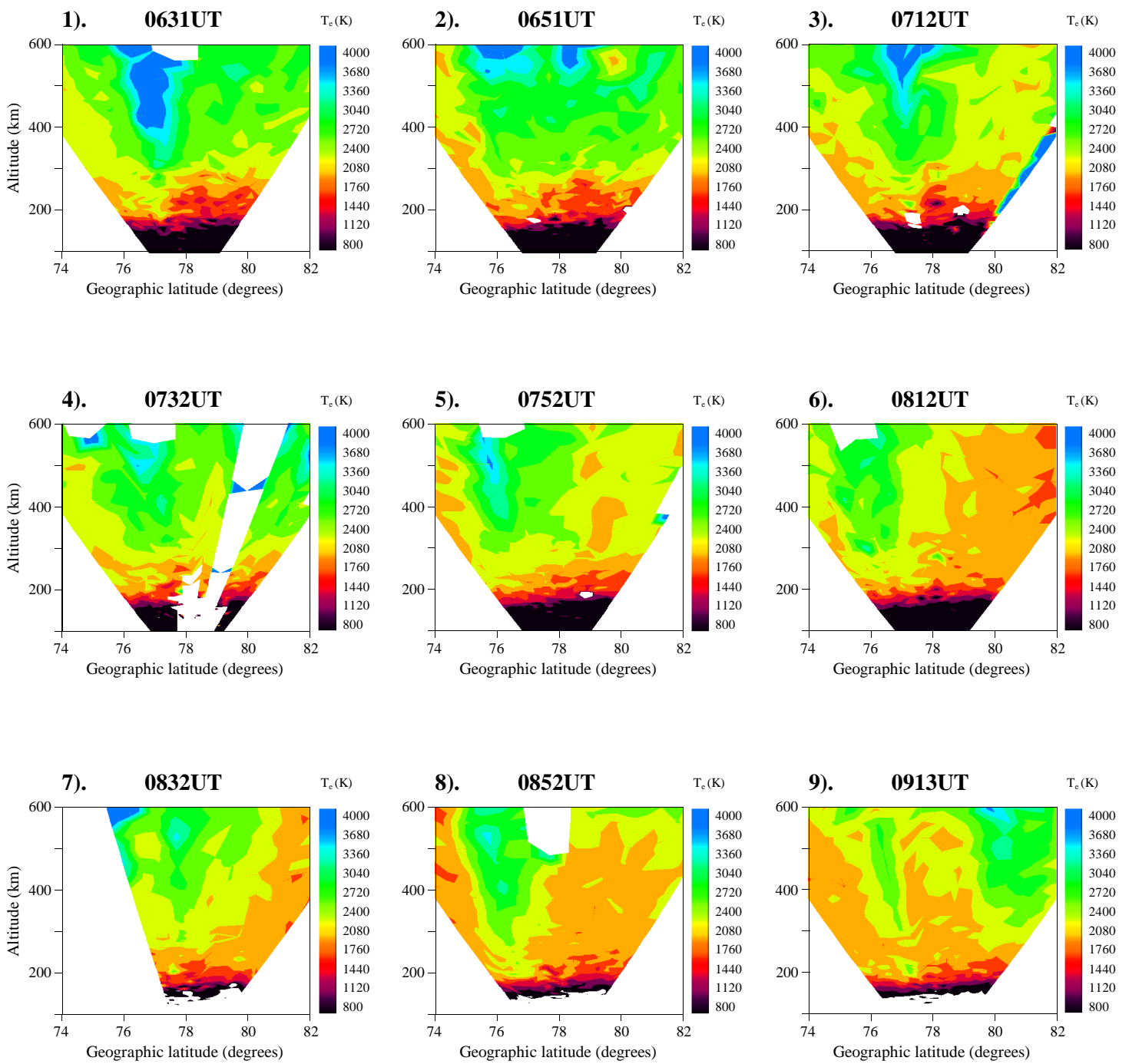

Fig. 3. Electron temperatures measured by the ESR corresponding to the electron densities presented in Fig. 2.

scan starting at 09:13 UT this extended region of high electron densities has a pronounced poleward edge near $79.5^{\circ} \mathrm{N}$ $\left(\sim 76.5^{\circ} \mathrm{MLAT}\right)$. Further north there is a density trough centered at $80.0^{\circ} \mathrm{N}\left(\sim 77.0^{\circ}\right.$ MLAT $)$ with a poleward wall at the northern extreme of the field-of-view.

Corresponding measurements of the electron temperature indicates that a region of precipitation occurs broadly between $76.0^{\circ}-78.0^{\circ} \mathrm{N}\left(\sim 73.0^{\circ}-75.0^{\circ} \mathrm{MLAT}\right)$ throughout the interval of interest (Nilsson et al., 1994). The precipitation is relatively soft and exhibits variability in both location and magnitude, generally becoming latitudinally confined with time. This is shown in the $3040-\mathrm{K}$ contour between the first and eighth radar scan that decreases from around $2.0^{\circ}$ to $1.0^{\circ}$ in latitudinal extent at an altitude of $400 \mathrm{~km}$. A separate event is observed during the scan starting at 08:32 UT, where a region of enhanced electron temperatures occur at high altitudes just south of zenith. Whilst this region is relatively weak it is clearly distinct from the soft precipitation further south. Away from regions of precipitation the electron temperatures are generally cool and are likely to represent background levels. There is, however, a region of enhanced electron temperatures during the final scan at 09:13 UT in the northern field-of-view that exhibits a sharp equatorward edge near $79.5^{\circ} \mathrm{N}\left(\sim 76.5^{\circ} \mathrm{MLAT}\right)$.

In light of the electron temperature measurements, and taking into account radar geometry (see Fig. 4), it is clear that the dense patch of plasma observed at 07:12 UT in the pre-noon sector was not being produced in-situ by soft particle precipitation at the time of observation, but comprised cold solar-produced ionisation that had convected into the radar beam. This interpretation is re-enforced by the high altitude of the enhancement and its relatively sharp bottomside profile, with plasma having recombined at the lower altitudes but remaining at high altitudes where the lifetime is longer. The appearance of this dense patch of plasma in the ESR field-of-view coincides with a weakening negative $B_{y}$ component of the IMF that may modify the entry region of solar ionisation, or TOI, into the polar cap (Sojka et al., 


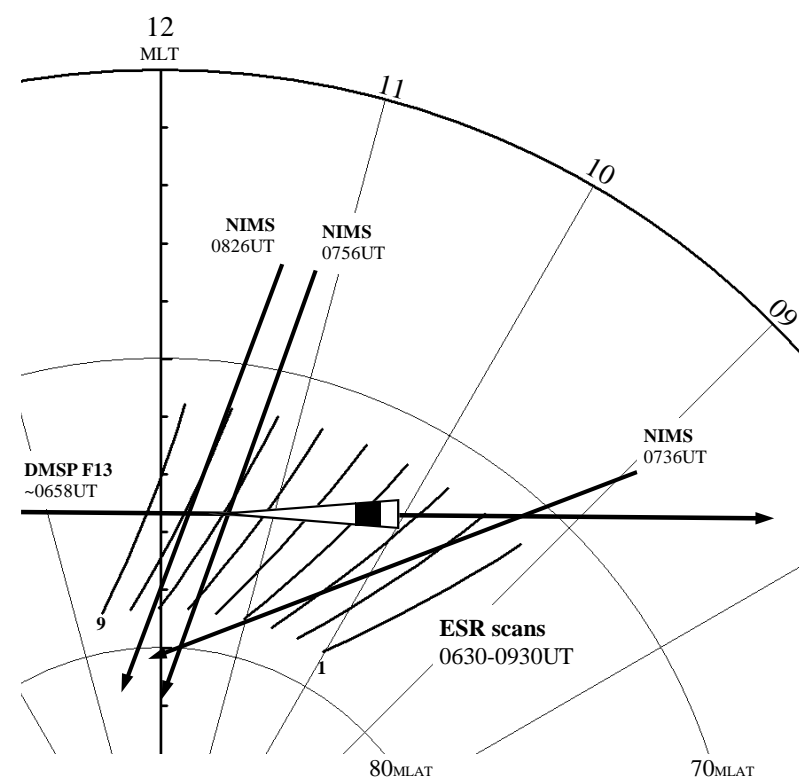

Fig. 4. Plot showing the geometry of the observations on a MLAT versus MLT polar grid. The location of the ESR radar beam during successive radar scans is shown broadly between 09:00-13:00 MLT with labels indicating the starting position of the first (1) and last (9) radar scan. Also shown are the trajectories of three northbound NIMS satellites at 07:36 UT, 07:56 UT and 08:26 UT where the arrows indicate the direction of satellite motion. The dusk-to-dawn trajectory of the DMSP F13 satellite is shown by the thick horizontal black line, with the black arrow at the pre-noon extent of the trajectory indicating the direction of satellite motion. The white triangle with a small black shaded region superimposed on the satellite trajectory broadly between 10:00-11:00 MLT indicates the extent of the ion dispersion signature and region of cusp precipitation, respectively.

1994). The appearance of this patch produced a narrow density trough at slightly lower latitudes with no evidence for increased chemical recombination in measurements of the ion temperature (not shown). At lower latitudes between $76.0^{\circ}-$ $78.0^{\circ} \mathrm{N}\left(\sim 73.0^{\circ}-75.0^{\circ}\right.$ MLAT $)$ structured electron densities are being produced in-situ by soft particle precipitation.

A transition into the noon sector is observed during the sixth radar scan starting at 08:12 UT, where latitudinally extended regions of higher electron densities are observed essentially across the field-of-view. This can partly be attributed to increased levels of solar EUV ionisation as the radar approaches local geographic noon (see Fig. 4), but the lack of any significant horizontal gradients in electron density suggests this feature is the TOI in the magnetic noon sector. The increasing peak height with latitude can be attributed to both the geometrical effect of increasing solar zenith angle with latitude, and the plasma recombination rate at lower altitudes as the ionisation is drawn into the polar cap to form the TOI. The role of soft particle precipitation in modulating the electron density at lower latitudes appears to be having only a secondary effect on the density structure, attributed to its superposition on such a large background density levels in
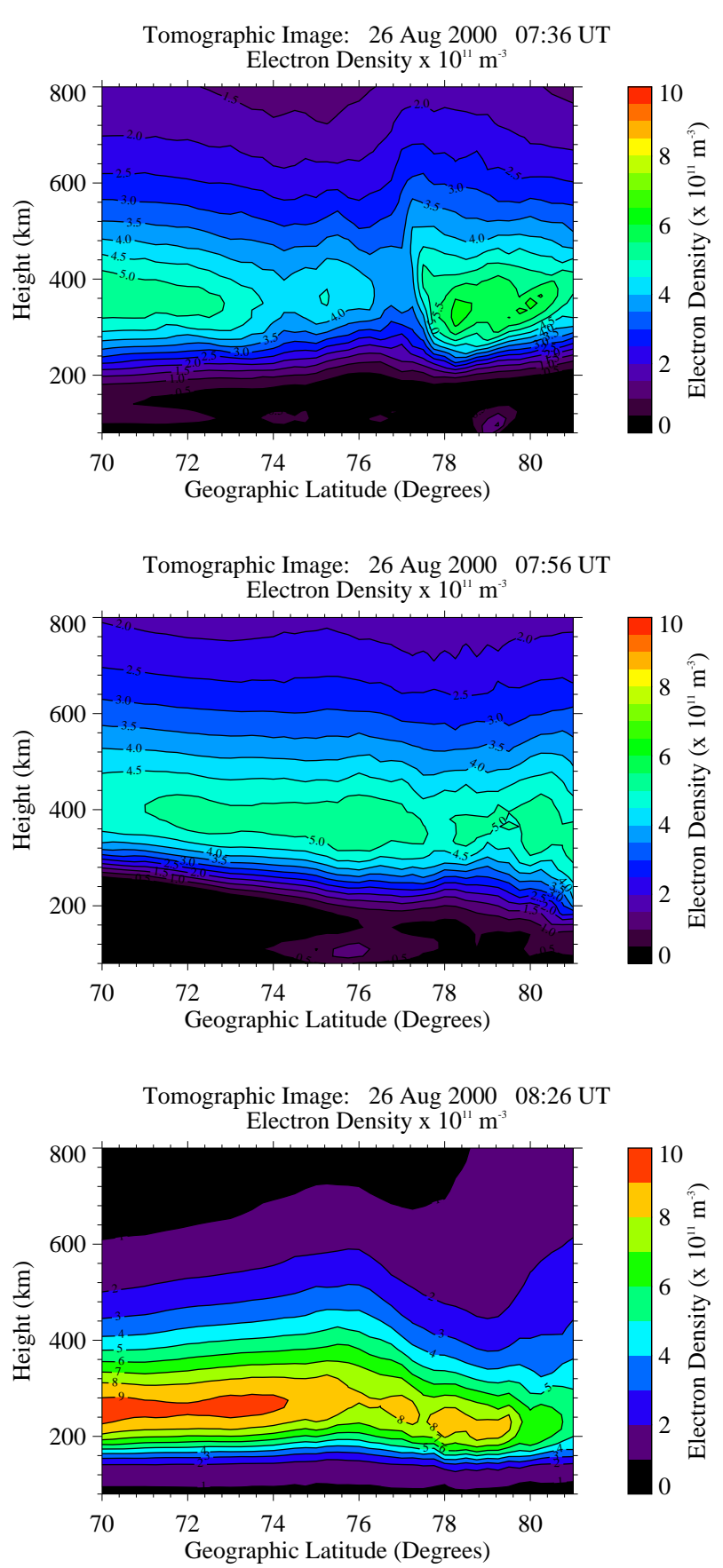

Fig. 5. Tomographic images of the spatial distribution of electron density during three satellite passes crossing a latitude of $75.0^{\circ} \mathrm{N}$ at 07:36 UT (upper panel), 07:56 UT (centre panel) and 08:26 UT (lower panel) plotted as a function of height and geographic latitude.

summertime. The only anomaly is the marked density trough observed during the scan starting at 08:32 UT that is likely to be associated with the weak trend in IMF $B_{y}$. This effect will be considered further in the discussion. The transition from the noon to the post-noon sectors is identified by the apparent pronounced poleward edge of the TOI in the scan starting at 09:13 UT with a density trough at the higher latitudes. The 
enhanced electron temperatures within this trough are consistent with the expected decrease in electron cooling rate in regions of depleted electron density (Banks and Kockarts, Academic Press, New York, 1973).

\subsubsection{Radio tomography}

Supporting information for the latitudinal distribution of electron density is provided by the radio tomography experiment operated by the University of Wales, Aberystwyth (Pryse, 2003). The tomography experiment comprises a chain of four receivers in Northern Scandinavia that monitor phase coherent signals from the polar orbiting satellites in the Navy Ionospheric Monitoring System (NIMS), previously know as the Navy Navigational Satellite System (NNSS), that enables the measurement of total electron content along a large number of intersecting satellite-to-receiver ray-paths. Inversion of the data yields the distribution of electron density over a meridional section of the polar ionosphere (for example Walker et al., 1998). Three satellite passes intersected $75.0^{\circ} \mathrm{N}$ at 07:36 UT, 07:56 UT and 08:12 UT and the reconstructed electron densities are shown in the three panels of Fig. 5. The 300-km ray-path intersection for these satellite passes are shown in magnetic coordinates in Fig. 4. The first tomographic image corresponding to the satellite pass at 07:36 UT is shown in the upper panel of Fig. 5. The tomographic image shows the spatial distribution of electron density in the pre-noon time sector broadly between 09:00-12:00 MLT (see Fig. 4). A density trough with a minimum density of $3.5 \times 10^{11} \mathrm{~m}^{-3}$ is centered at $77.0^{\circ} \mathrm{N}\left(\sim 75.0^{\circ}\right.$ MLAT) with a broad region of enhanced electron densities at lower latitudes. To the north of the trough is a patch of plasma between $77.5^{\circ}-81.0^{\circ} \mathrm{N}\left(\sim 75.5^{\circ}-\right.$ $78.3^{\circ}$ MLAT) with a maximum density of $6.0 \times 10^{11} \mathrm{~m}^{-3}$.

The second tomographic image corresponding to the satellite pass at 07:56 UT is shown in the middle panel of Fig. 5. The tomographic image shows the spatial distribution of electron density in the magnetic noon sector between 11:0012:00 MLT (see Fig. 4). A broad region of enhanced electron densities extend from low-to-high latitudes along the image characteristic of the TOI. The continued increase in electron density within the TOI is observed during the third tomographic image at 08:26 UT, where peak densities now reach $9.0 \times 10^{11} \mathrm{~m}^{-3}$ (lower panel of Fig. 5), with a hint of decreasing densities at the northern extreme of the image.

Comparison with ESR observations suggests that the spatial distribution imaged by tomography is consistent with the transition between the pre- and post-noon time sector. The pre-noon density trough and dense patch between $77.5^{\circ}-$ $81.0^{\circ} \mathrm{N}\left(\sim 75.5^{\circ}-78.3^{\circ}\right.$ MLAT) during the satellite pass at 07:36 UT is very similar to that observed by the ESR in both the radar scans starting at 07:12 UT and 07:32 UT. The observation of the TOI in the noon sector in the tomographic images at 07:56 UT and 08:26 UT is consistent with corresponding ESR observations in time at 07:52 UT and 08:12 UT respectively. The decreasing densities with increasing latitude in the northern extreme of the tomographic image at 08:26 UT is in agreement with the slight depletion observed at the northern extreme of the ESR scan starting at 08:12 UT. This edge effect is most pronounced during a later ESR scan starting at 09:13 UT, where a density trough at very high latitudes is suggested to mark a transition into the post-noon time sector. The absolute densities measured by tomography are in good agreement with ESR observations during the interval of interest, although the peak height is not so well reproduced, becoming progressively displaced in altitude in comparison to ESR observations. The discrepancy in the altitude is attributed to the incomplete observing geometry of tomography that leads to reduced information about the vertical profile of the ionisation distribution. Whilst this affects all reconstructions to some extent, it has its most pronounced effect where there is a lack of horizontal structure, such as the last two images (Pryse et al., 1998).

\subsection{High-latitude plasma flow}

\subsubsection{SuperDARN HF radars}

Observations by the SuperDARN network of HF radars have been used to estimate the global high-latitude convection pattern throughout the interval of interest (Greenwald et al., 1990). Line-of-sight velocity measurements were used to constrain IMF-dependant empirical convection models based on statistically derived convection patterns by Ruohoniemi and Greenwald (1996), to obtain a map of the electric potential (Ruohoniemi and Greenwald, 1998). Selected outputs are shown in Fig. 6 for four time periods covering the transition between the pre- and post-noon time sectors identified by the ESR. These plots were chosen where there was sufficient backscatter within the Svalbard region, although this was not possible for the final period between 09:1009:12 UT. The electric potentials have been plotted on a MLAT versus MLT polar grid, equivalent to that shown in Fig. 4, with magnetic noon at the top of each output. The location of zenith and extent of the ESR scan corresponding to each output is shown on the figure by the red marker and black line, respectively.

Of interest in the current study is a clear two-cell convection pattern that is consistent with the pertinent IMF conditions (Cowley, 1998). The weak trend in the $B_{y}$ component shown in Fig. 1 is likely to have a secondary effect by introducing asymmetries into the convection pattern (Cowley and Lockwood, 1992). At the beginning of the interval of interest the $B_{y}$ component is negative and the entry region is expected to be rotated towards earlier MLTs. This is observed with the output at 06:40-06:42 UT, where flows in excess of $600 \mathrm{~ms}^{-1}$ are directed towards the post-noon sector. As the $B_{y}$ component weakens and approaches zero the convection pattern becomes much more symmetrical around magnetic noon. This is observed during the next output at 08:10-08:12 UT, where flows in excess of $500 \mathrm{~ms}^{-1}$ are directed along the noon-midnight meridian. Subsequently the $B_{y}$ component becomes weakly positive which would cause the rotation of the entry region towards later MLTs. This is 
a). 0640-0642UT

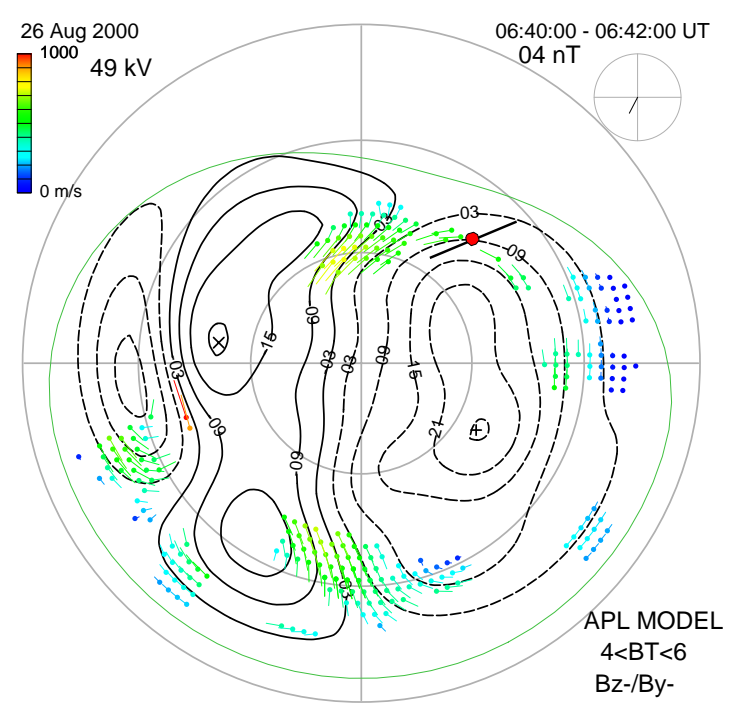

c). 0830-0832UT

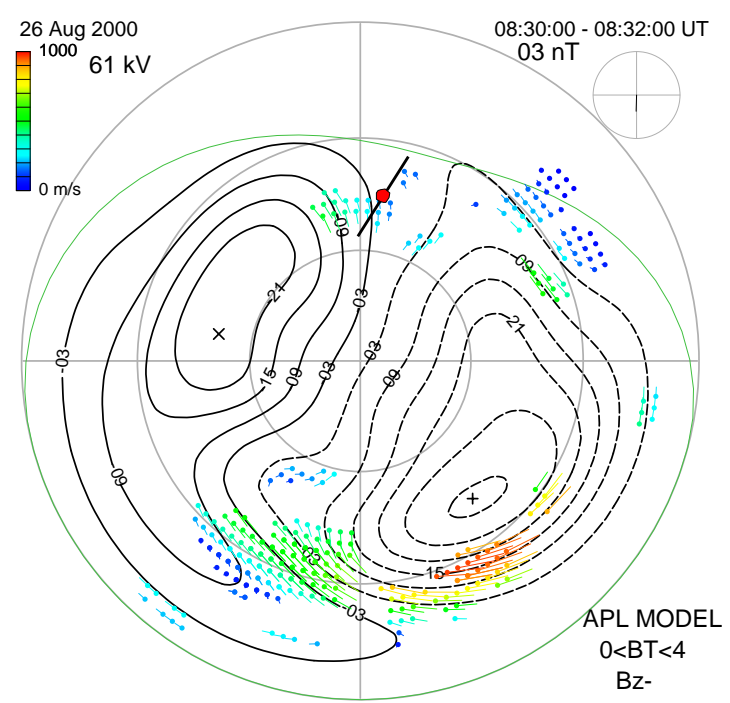

b). 0810-0812UT

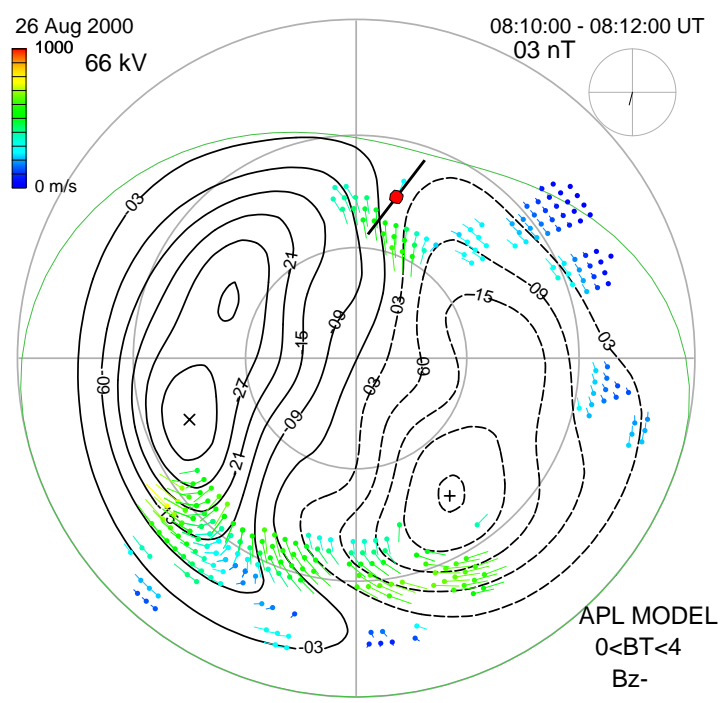

d). 0910-0912UT

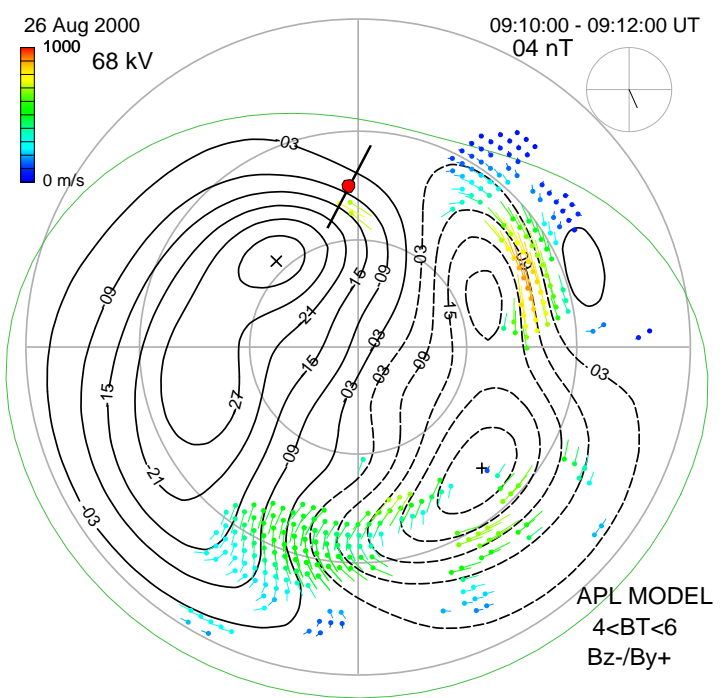

Fig. 6. Selected electric potential maps derived from line-of-sight velocity measurements from the SuperDARN HF radars broadly between 06:30-09:30 UT on 26 August 2000.

observed during the third output at 08:30-08:32 UT and the fourth output at 09:10-09:12 UT, albeit with much less scatter, where flows in excess of $400 \mathrm{~ms}^{-1}$ are directed into the pre-noon sector.

During the first output between 06:40-06:42 UT the ESR is located to the west of the expected location of the TOI, where it observes the spatial distribution of electron density in the pre-noon time sector. Comparison with the electric potentials suggests that the dense patch of plasma at highlatitudes during the radar scan starting at 07:12 UT occurs on antisunward convecting field lines, consistent with the interpretation that it comprises solar-produced ionisation that is entering the polar cap as a TOI. The narrow density trough at slightly lower latitudes also appears to reside on antisunward convecting field lines, whereas the structured electron densities further south are broadly coincident with the centre of the pre-noon convection cell. As the ESR moves closer to magnetic noon between 08:10-08:12 UT the radar beam becomes aligned essentially along the noon-midnight magnetic meridian. Measurements of the IMF from the ACE spacecraft during this period suggest that the $B_{y}$ component is of very weak magnitude (see Fig. 1). A region of high electron densities spans the entire latitudinal range of the scan during this time period that are interpreted as being the TOI. The 


\section{F13 26 Aug 2000}

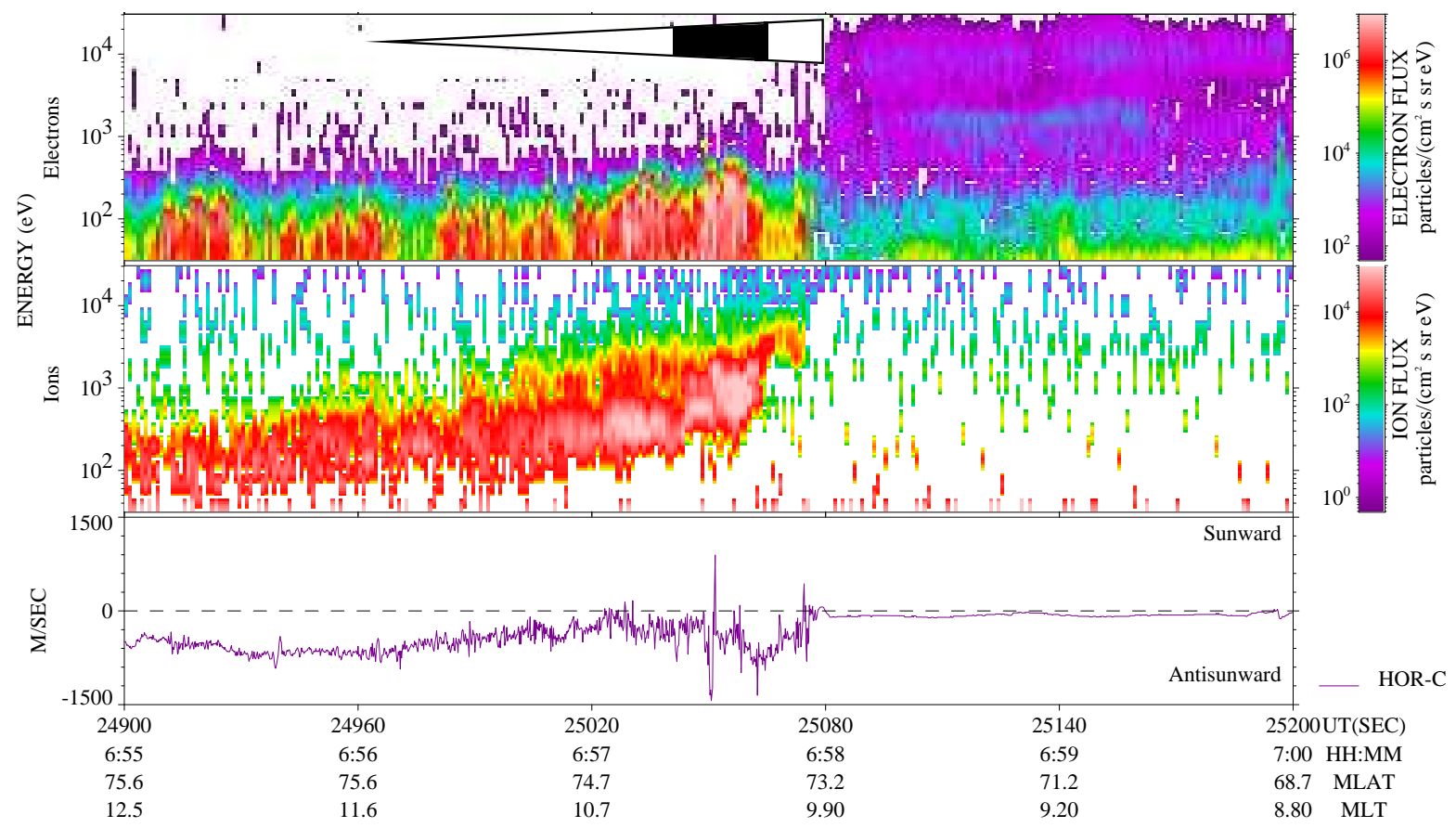

Fig. 7. Electron and ion flux spectra (upper two panels) and the horizontal component of cross-track ion drift (lower panel) for the pass of the DMSP F13 satellite between 06:55-07:00 UT. The extent of the ion dispersion is shown at the top of the electron spectra panel by the white triangle, consistent with Fig. 4.

$B_{y}$ component subsequently becomes positive, and the entry region is observed to rotate to later MLTs during the outputs at 08:30-08:32 UT and 09:10-09:12 UT. During the latter output the ESR radar is located within the post-noon time sector where the TOI is observed to extend to $79.5^{\circ} \mathrm{N}$ with a density trough located further north. Comparison with the electric potentials suggests that this density trough is coincident with plasma well-inside the post-noon convection cell. Measurements of the component of ion velocity along the line-of-sight of the ESR radar beam (not shown) throughout the time interval are consistent with SuperDARN observations.

\subsubsection{Defence Meteorological Satellite Program}

Further experimental support for the anticipated convection pattern was provided by measurements made by the F13 satellite of the Defence Meteorological Satellite Programme (DMSP). The satellite followed an essentially eastto-west trajectory across the dayside ionosphere crossing magnetic noon near 75.6 $6^{\circ}$ MLAT at 06:55 UT. Of particular interest is the pre-noon section of this satellite pass that is shown in magnetic co-ordinates in Fig. 4 by the horizontal black line. Measurements of the cross-track horizontal component of ion drift along the satellite trajectory is shown in the lower panel of Fig. 7. The negative values between 06:55-06:58 UT indicate that an antisunward flow component was measured as the satellite passed from the noon to the pre-noon time sector broadly between $75.6^{\circ}-$ 73.2 $2^{\circ}$ MLAT and 12:30-09:54 MLT, consistent with SuperDARN observations (Fig. 6a). An abrupt weakening of the antisunward component is observed near $73.2^{\circ}$ MLAT with near-zero values thereafter. Whilst it is possible that the abrupt weakening of the flow may have occurred as the satellite trajectory aligned with the direction of plasma flow, the persistence of the low values to lower latitudes is likely to suggest that the satellite has moved out of the high-latitude convection regime to that at lower latitudes.

Complementary measurements of the electron and ion spectra shown in the top two panels of Fig. 7 show characteristics of cusp precipitation (Newell and Meng, 1988). Ion energies of $\sim 10^{3} \mathrm{eV}$ and electron energies of $\sim 10^{2} \mathrm{eV}$ occur between $74.2^{\circ}-73.7^{\circ}$ MLAT within a region of ion dispersion. This precipitation, embedded within a region of antisunward plasma flow, provides evidence for magnetopause reconnection during IMF $B_{z}<0$ conditions (Newell and Meng, 1991, 1995). The extent of the dispersion signature is shown by the white triangle, directed opposite to satellite motion, superimposed on the satellite trajectory in Fig. 4 and above the electron spectra panel in Fig. 7. The base of the triangle near 73.2 ${ }^{\circ}$ MLAT and 09:54 MLT indicates the location of a drop-out of $\sim \mathrm{keV}$ electrons and equatorward edge of energetic ion precipitation, whereas the apex of the triangle near 75.2 $2^{\circ}$ MLAT and 11:30 MLT indicates the extent of the low-energy tail of softer precipitation. 


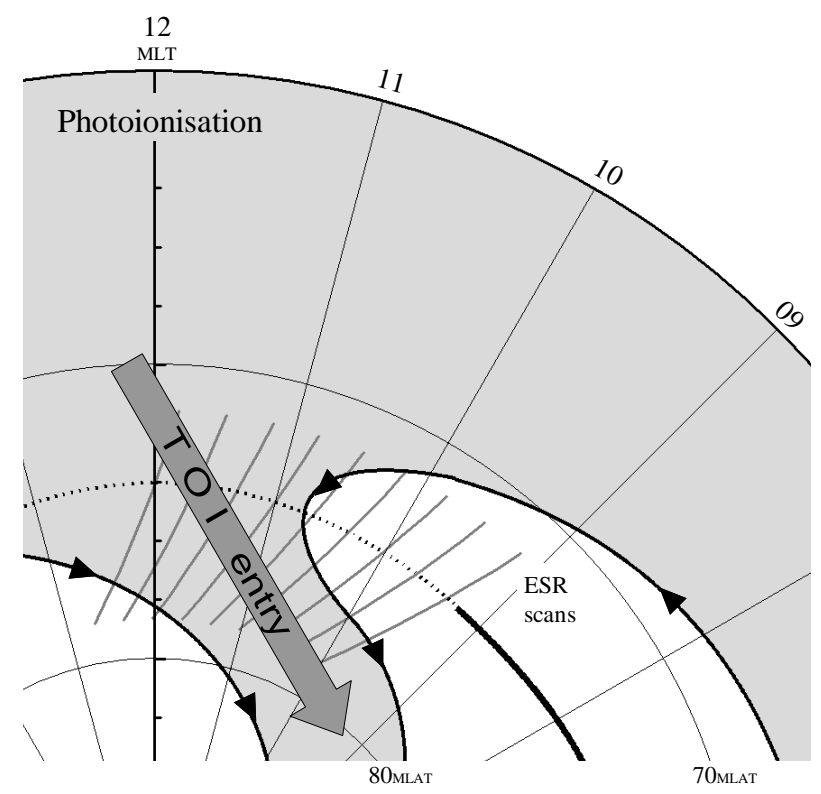

Fig. 8. Summary schematic showing the main observed features on a MLAT versus MLT polar grid during the $B_{y}>0$ and $B_{z}<0$ conditions near the end of the time interval. Superimposed are convection streamlines with the large grey arrow indicating the entry of the TOI, flanked by depletions in electron density on its pre- and post-noon sides.

The black shaded section near the base of the triangle indicates the location of cusp precipitation. The drop-out of $\sim \mathrm{keV}$ electrons near $73.2^{\circ}$ MLAT is in close proximity to the $30 \mathrm{keV}$ electron trapping boundary identified by a NOAA 15 satellite $10 \mathrm{~min}$ previously (not shown). These boundaries may be used as a proxy for the open/closed magnetic fieldline boundary (OCLFB) (Sotirelis et al., 1998; Moen et al., 1996, 1998).

Comparison with ESR observations indicate that the region of ion dispersion and cusp precipitation is coincident with the region of soft precipitation observed by the radar between $76.0^{\circ}-78.0^{\circ} \mathrm{N}\left(\sim 73.0^{\circ}-75.0^{\circ}\right.$ MLAT $)$ that resulted in structured F-region electron densities. The drop-out of $\sim \mathrm{keV}$ electrons and the abrupt weakening of antisunward plasma flow are both coincident with the equatorward edge of the region of structured electron densities. This suggests that both the dense patch of plasma and resulting narrow density trough subsequently observed by the ESR occur on open, antisunward convecting field lines, consistent with $\mathrm{Su}-$ perDARN observations.

\section{Discussions and Conclusions}

ESR observations have been presented of large-scale spatial structure in the summertime dayside ionospheric plasma under conditions of IMF $B_{z}<0$. Multi-instrument observations from radio tomography, a DMSP satellite and the SuperDARN radars have been used to distinguish between spatial and temporal changes in the structuring of the density features. Interplanetary and geomagnetic conditions during the period of interest were relatively constant, allowing the study to focus on the spatial distribution of plasma. A weak trend of increasing IMF $B_{y}$ did, however, give rise to a temporal variation in density as IMF $B_{y}$ changed polarity, but its effect was only of secondary importance to the study. Central to the study were observations of the tongue-of-ionisation transporting plasma from sub-auroral latitudes into the polar cap identified by the ESR as it rotated beneath what are essentially fixed features. Inspection of successive radar scans revealed that the TOI was extended in latitude but confined in longitude, being flanked on the dawn and dusk sides by depletions in electron density. Earlier modelling studies (Bowline et al., 1996) have provided images of such spatial structure, but observations of the latitudinal structure of such features to substantiate the model output have been few in this remote and inhospitable region of the globe.

To aid the interpretation of the measurements from the different instruments, the distribution of photoionisation observed during the study has been plotted in geomagnetic coordinates in Fig. 8. The figure is similar to that shown in Fig. 4, containing only the location of the ESR radar scans, and has been constructed for $B_{y}>0$ and $B_{z}<0$ conditions near the end of the time interval. It shows the entry of photoionisation into the pre-noon time sector with regions of depleted densities (no shading) flanking the TOI on its pre- and post-noon sides. Superimposed are thick black arrowed curves that represent the possible high-latitude convection pattern consistent with SuperDARN and DMSP observations and the theoretical convection patterns by Cowley (1998). The thick black curve at the centre of the pre-noon convection cell extending to approximately 09:15 MLT indicates the likely location of the non-reconnecting segment of the OCLFB, whereas the dashed line thereafter indicates the broad location of soft particle precipitation identified by both the ESR and a DMSP satellite.

The peak height of dayside F-region summertime plasma is expected to increase with latitude as the solar zenith angle increases. Simple calculations at an altitude of $300 \mathrm{~km}$ indicate that the solar zenith angle increases from approximately $61.0^{\circ}-66.0^{\circ}$ between $74.0^{\circ}-82.0^{\circ} \mathrm{N}$ along the geographic scanning meridian of the ESR near magnetic noon. According to Chapman theory this would produce a gradient in the peak height with latitude that would increase by approximately $18 \%$ that of the F-region scale height over the latitude range of interest. This represents only a small increase in peak height along the ESR field-of-view that is consistent with the observations of the TOI (Fig. 2). This gradient may also be attributed to the chemical recombination processes becoming increasingly important at higher latitudes where the rate of photoionisation decreases. These loss processes will remove ionisation from lower F-region altitudes much more quickly than at higher altitudes, owing to the much lower neutral particle density, enabling plasma at F-region altitudes to have a lifetime of many hours. In addition to the peak height, the peak density of the F-region is also expected to exhibit a latitudinal gradient with electron 
density decreasing with increasing latitude. Simple calculations based on Chapman theory indicate that the ionisation production rate will decrease by some $15 \%$ over the latitude range of interest, although the observed peak electron density within the TOI remained relatively uniform. There is, however, some evidence for in-situ production by softparticle precipitation, causing the slight modulation of the large dayside summertime densities. Thus, the uniformity of the peak F-region electron density supports plasma transport from lower latitudes as being important for creating the TOI.

The TOI is interrupted in the scan starting 08:32 UT by the appearance of a localised density trough at a latitude of $78.0^{\circ} \mathrm{N}\left(\sim 75.0^{\circ} \mathrm{MLAT}\right)$, commensurate with that of the prenoon high-latitude trough of earlier scans. Its appearance may be attributed to the weak trend in the $B_{y}$ component, with positive values after about 08:30 UT rotating the prenoon density trough and the entry of the TOI to later MLTs. Modelling studies by Bowline et al. (1996), using the Utah State University TDIM model, investigated the spatial distribution of electron density under IMF $B_{z}<0$ conditions for both IMF $B_{y}$ polarities. Figure 7 of their paper, for IMF $B_{y}$ positive, shows the lower densities of the pre-noon trough extending to later MLTs and the TOI entering the polar cap from the post-noon time sector. The reappearance of the uninterrupted TOI in the ESR scan starting at 08:52 UT is then attributed to the radar "catching up" with the TOI at later MLTs.

Within the pre-noon time sector the radar is likely to observe a cross section of the TOI rather than align along the feature. The cross section is first observed north of zenith during the radar scan starting at 07:12 UT and subsequently at lower latitudes and altitudes during successive scans. Although this feature is observed at an early UT, the enhancement is attributed to an intersection through a mature region of the TOI that had entered the polar cap near the magnetic noon meridian at an earlier time that has subsequently been drawn antisunward by high-latitude convection into the fieldof-view of the ESR in the pre-noon sector (see Fig. 8). The low electron temperatures of the enhancement are in accord with plasma produced at an earlier time, and the high altitude of the feature is consistent with recombination processes that remove the plasma from lower F-region altitudes. This effect can be seen in successive scans starting at 07:12 UT, where the altitude of the feature decreases and the density of the enhancement increases as the radar moves towards magnetic noon under a relatively unchanging ionospheric spatial structure.

The TOI cross section in the scan starting 07:12 UT gives a TOI-to-background density of some 2.2 , where the peak value was taken as $5.5 \times 10^{11} \mathrm{~m}^{-3}$ and the background has been taken at $2.5 \times 10^{11} \mathrm{~m}^{-3}$ before the main appearance of the feature in the scan starting at 06:51 UT. The modelling study of Sojka et al. (1994) investigated polar ionisation patches and their density in relation to the background level. The patches were created by temporal changes in IMF $B_{y}$, allowing the comparison of their patch-to-background ratio to the TOI-to-background ratio determined in the current study.
For the pertinent summer conditions the model found that patches of high density were most marked between 06:0009:00 UT, with a patch-to-background ratio of about 1.5, much lower than the observed value of the current study. The subsequent study of Bowline et al. (1996) that took into account the polarity of IMF $B_{y}$ and the location of the observing station, suggested that patches at Ny Ålesund were most marked between the pre-noon to noon time sectors, specifically between 08:00-09:00 UT for positive $B_{y}$ and 07:0009:00 UT for negative $B_{y}$ (Fig. 7 of Bowline et al., 1996). In these cases the patch-to-background ratios were 2.4 and 2.2 , respectively, in good agreement with that observed in the current study. The modelled ratio is very similar for both IMF $B_{y}$ polarities in the summer, being most marked generally between 07:00-09:00 UT. This is broadly consistent with the results presented earlier by Sojka et al. (1994), although the ratio reported by Bowline et al. (1996) is much higher.

The appearance of the density enhancement in the pre-noon time sector in the ESR radar scan starting at 07:12 UT produces a narrow density trough near $78.0^{\circ} \mathrm{N}$ $\left(\sim 75.0^{\circ}\right.$ MLAT) with a minimum density of $1.5 \times 10^{11} \mathrm{~m}^{-3}$. The trough persists during the next radar scan starting at 07:32 UT with normal levels of both the ion and electron temperature. Inspection of SuperDARN and DMSP observations suggests that the trough resides on open, antisunward convecting field lines just north of the OCFLB and region of soft particle precipitation. This is contrary to observations of the high-latitude density trough by ground-based sounding experiments (Whalen, 1989) and radar measurements (Foster and Doupnik, 1984), where it was suggested to occur on sunward convecting field lines. The review paper by Rodger et al. (1992) suggested that the high-latitude trough in the pre-noon time sector may occur near the CRB. Another classification of trough is cited by Rodger et al. (1992) to represent a normal ionosphere between adjacent polar patches. These troughs occur deep in the polar cap with normal values of both electron and ion temperature. It is likely that the trough in the current study falls into the same classification, although in this instance it is not delineated by adjacent polar patches but a region of photoionisation constituting the TOI at its poleward edge and a region of structured plasma created by soft precipitation at its equatorward edge.

The transition into the post-noon sector is identified in the ESR scan starting at 09:13 UT, where the TOI exhibits a clear poleward edge at the higher latitudes of the field-ofview. To the north is a density trough, with coincident enhanced electron temperatures, that is consistent with electron cooling in regions of depleted electron densities (Banks and Kockarts, Academic Press, New York, 1973). The trough has a minimum density of around $3.5 \times 10^{11} \mathrm{~m}^{-3}$ centered near $80.0^{\circ} \mathrm{N}\left(\sim 77.0^{\circ}\right.$ MLAT). This transition into the postnoon regime is supported by the SuperDARN electric potential maps with the radar observing entirely within the dusk convection cell (see Fig. 6d). The transportation of low densities from the nightside by high-latitude convection plays a role in the formation of the trough, consistent 
with ground-based observations by Whalen $(1987,1989)$ and radar measurements by Foster and Doupnik (1984); Foster et al. (1989). The modelled plasma distribution of Bowline et al. (1996) indicates the locations of the pre- and postnoon high-latitude troughs during positive IMF $B_{y}$ conditions around $70.0^{\circ}$ MLAT and $78.0^{\circ}$ MLAT, respectively, some $8.0^{\circ}$ apart. Whilst the observations in the current study indicate a smaller displacement of around $2.0^{\circ}$, the pre-noon trough was clearly at a lower latitude than the post-noon trough.

In summary, the ESR has provided unique observations of the high-latitude large-scale plasma structure in summer under conditions of $B_{z}<0$, in particular the TOI and the pre- and post-noon high-latitude troughs. These are in general agreement with modelling by the Utah State University Group under similar conditions. The multi-instrument observations of the current study, and their comparison with the model output, indicate the dominance of the high-latitude convection pattern in structuring the plasma. Further observations of the spatial structure of the TOI are required to establish the dependance of its location with season, IMF orientation and amount of solar ionisation, and to address the details of the processes responsible for the structuring of plasma.

Acknowledgements. Financial support for the project was provided by the UK Particle Physics and Astronomy Research Council under grant PPA/G/O/2001/00012. The assistance of the University of Troms $\varnothing$ and the Norwegian Polar Research Institute in the tomographic measurements is gratefully acknowledged. SuperDARN radar facility is funded by National Research Programs of the UK, Sweden, Finland, France, USA, Canada, Japan, South Africa and Australia; the figures presented here were provided by M. Lester from the University of Leicester. EISCAT is an international facility supported by the national science councils of Finland, France, Germany, Japan, Norway, Sweden and the United Kingdom. The ACE data were provided by N. Ness and obtained from the CDAWeb, NASA.

Topical Editor M. Lester thanks two referees for their help in evaluating this paper.

\section{References}

Anderson, D., Buchau, J., and Heelis, R.: Origin of density enhancements in the winter polar cap ionosphere, Radio Sci., 23, 513-519, 1988.

Banks, P. and Kockarts, G.: Aeronomy, Academic Press, New York, 1973.

Bowline, M., Sojka, J., and Schunk, R.: Relationship of theoretical patch climatology to polar cap patch observations, Radio Sci., 31, 635-644, 1996.

Buchau, J., Reinisch, B., Weber, E., and Moore, J.: Structure and dynamics of the winter polar cap F region, Radio Sci., 18, 9951010, 1983.

Buchau, J., Reinisch, B., Anderson, D., Weber, E., and Dozois, C.: Polar cap plasma convection measurements and their relevance to the modelling of the high-latitude ionosphere, Radio Sci, 23, 521-536, 1988.

Cowley, S.: Excitation of flow in the Earth's MagnetosphereIonosphere system: observations by incoherent-scatter radar, in:
Polar Cap Boundary Phenomenon, edited by Moen, J., Egeland, A., and Lockwood, M., NATO Advanced Study InstituteSeries, Kluwer Academic Press, Dordrecht, The Netherlands, 127-140, 1998.

Cowley, S. and Lockwood, M.: Excitation and decay of Solar wind-driven flows in the magnetosphere-ionosphere system, Ann. Geophys., 10, 103-115, 1992.

Crowley, G.: Critical review of ionospheric patches and blobs, in: URSI Review of Radio Science 1993-1996, edited by Stone, W. R., published for the International Union of Radio Science by the Oxford University Press, 619-648, 1996.

Foster, J.: Ionospheric signatures of magnetospheric convection, J. Geophys. Res., 89, 855-865, 1984.

Foster, J.: Storm time plasma transport at middle and high latitudes, J. Geophys. Res., 98, 1675-1689, 1993.

Foster, J. and Doupnik, J.: Plasma convection in the vicinity of the polar cusp, J. Geophys. Res., 89, 9107-9113, 1984.

Foster, J., Yeh, H.-C., Holt, J., and Evans, D.: Two-dimensional mapping of dayside convection, in: Electromagnetic Couping in the Polar Clefts and Caps, edited by Sandholt, P. and Egeland, A., Kluwer Academic, Boston, Mass., 115-125, 1989.

Greenwald, R., Baker, K., Ruohoniemi, J., Dudeney, J., Pinnock, M., Mattin, N., Leonard, J., and Lepping, R.: Simultaneous conjugate observations of dynamic variations in high-latitude dayside convection due to changes in IMF $B_{y}$, J. Geophys. Res., 95, 8057-8072, 1990.

Kelly, J. and Vickrey, J.: F-region ionospheric structure associated with anti-sunward flow near the dayside polar cusp, Geophys. Res. Lett., 11, 907-910, 1984.

Knudsen, W.: Magnetospheric convection and the high latitude F2 ionosphere, J. Geophys. Res., 79, 1046-1055, 1974.

Lockwood, M. and Carlson, H.: Production of polar-cap electrondensity patches by transient magnetopause reconnection, Geophys. Res. Lett., 19, 1731-1734, 1992.

Lockwood, M., Sandholt, P., Cowley, S., and Oguti, T.: Interplanetary magnetic-field control of the dayside auroral activity and the transfer of momentum across the dayside magnetopause, Planet. Space Sci., 37, 1347-1365, 1989.

Moen, J., Evans, D., Carlson, H., and Lockwood, M.: Dayside moving auroral transients related to LLBL dynamics, Geophys. Res. Lett., 23, 3247-3250, 1996.

Moen, J., Lorentzen, D., and Sigernes, F.: Dayside moving auroral forms and bursty proton auroral events in relation to particle boundaires observed by NOAA-12, J. Geophys. Res., A7, 14 855-14 863, 1998.

Moffett, R. and Quegan, S.: The mid-latitude trough in the electronconcentration of the ionospheric F-layer - A review of observations and modeling, J. Atmos. and Terr. Phys., 45, 315-343, 1983.

Newell, P. and Meng, C.-I.: The cusp and the cleft/LLBL: Lowaltitude identification and statistical local time variation, J. Geophys. Res., A12, 14 549-14 556, 1988.

Newell, P. and Meng, C.-I.: Ion acceleration at the equatorward edge of the cusp: Low-altitude observations of patchy merging, Geophys. Res. Lett., 18, 1829-1832, 1991.

Newell, P. and Meng, C.-I.: Cusp low-energy ion cutoffs: A survey and implications for merging, J. Geophys. Res., 100, $21943-$ $21951,1995$.

Nilsson, H., Kirkwood, S., Eliasson, L., and Norberg, O.: The ionospheric signature of the cusp: A case study using Freja and the Sondrestrom radar, Geophys. Res. Lett., 21, 1923-1926, 1994.

Pryse, S.: Radio tomography: A new experimental technique, Sur- 
veys in Geophysics, 24, 1-38, 2003.

Pryse, S., Kersley, L., Williams, M., and Walker, I.: The spatial structure of the dayside ionospheric trough, Ann. Geophys., 16, 1169-1179, 1998,

SRef-ID: 1432-0576/ag/1998-16-1169.

Pryse, S., Sims, R., Moen, J., Kersley, L., Lorentzen, D., and Denig, W.: Evidence for solar production as a source of polarcap plasma, Ann. Geophys., 22, 1093-1102, 2004,

SRef-ID: 1432-0576/ag/2004-22-1093.

Rodger, A., Moffett, R., and Quegan, S.: The role of ion drift in the formation of ionization troughs in the midlatitude and highlatitude ionosphere - A review, J. Atmos. Terr. Phys., 54, 1-30, 1992.

Rodger, A., Pinnock, M., Dudeney, J., Baker, K., and Greenwald, R.: A new mechanism for polar patch formation, J. Geophys. Res., 99, 6425-6436, 1994.

Ruohoniemi, J. and Greenwald, R.: Statistical patterns of highlatitude convection obtained from Goose Bay HF radar observations, J. Geophys. Res., 101, 21 743-21 763, 1996.

Ruohoniemi, J. and Greenwald, R.: The response of high-latitude convection to a sudden southward IMF turning, Geophys. Res. Lett., 25, 2913-2916, 1998.

Sato, T.: Morphology of ionospheric $\mathrm{F}_{2}$ disturbances in the polar regions, Rep. Ionos. Space Res. Jpn., 13, 91-104, 1959.

Sims, R.: Signatures of Magnetospheric Processes in the HighLatitude Dayside Ionosphere, Ph.D thesis UWA, 2003.

Smith, A., Pryse, S., and Kersley, L.: Polar patches observed by ESR and their possible origin in the cusp region, Ann. Geophys., 18, 1043-1053, 2000,

SRef-ID: 1432-0576/ag/2000-18-1043.
Sojka, J., Bowline, M., and Schunk, R.: Patches in the polar ionosphere: UT and seasonal dependance, J. Geophys. Res., 99, 14 959-14 970, 1994.

Sotirelis, T., Newell, P., and Meng, C.-I.: Shape of the open-closed boundary of the polar cap as determined from observations of precipitating particles by up to four DMSP satellites, J. Geophys. Res., 103, 399-406, 1998.

Tsunoda, R.: High-latitude F-region irregularities - A review and synthesis, Rev. Geophys., 26, 719-760, 1988.

Walker, I., Moen, J., Mitchell, C., Kersley, L., and Sandholt, P.: Ionospheric effects of magnetopause reconnection observed using ionospheric tomography, Geophys. Res. Lett, 25, 293-296, 1998.

Walker, I., Moen, J., Kersley, L., and Lorentzen, D.: On the possible role of cusp/cleft precipitation in the formation of polar-cap patches, Ann. Geophys., 17, 1298-1305, 1999,

SRef-ID: 1432-0576/ag/1999-17-1298.

Weber, E., Buchau, J., Moore, J., Sharber, J., Livingston, R., Winningham, J., and Reinisch, B.: F-layer ionization patches in the polar-cap, J. Geophys. Res., 89, 1683-1694, 1984.

Whalen, J.: Daytime F-layer trough observed on a macroscopic scale, J. Geophys. Res., 92, 2571-2576, 1987.

Whalen, J.: The daytime F-layer trough and its relation to ionospheric-magnetospheric convection, J. Geophys. Res., 94, 17 169-17 184, 1989.

Whalen, J.: Properties of the F layer plasma in the midday throat ridge and trough, Radio Sci., 29, 219-230, 1994. 